\title{
ACERCA DE UN \\ IRRITANTE DEBATE ENTRE \\ ANTROPOLOGOS DEL NORTE
}

Comentarios al artículo de O. Starn

\section{Juan Ansión}

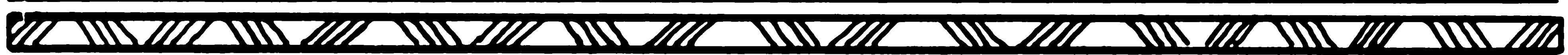

El ARTICULO DE Orin Starn, leído desde el Perú, desconcierta $e$ irrita. Quienes trabajamos desde las ciencias sociales para entender un país tan complejo como el Perú $y$, al mismo tiempo, seguimos apostando por hacer de él un país viable, tenemos derecho a preguntarnos acerca de lo que motiva aquella crítica tan dura de uno de los mejores trabajos que haya producido la antropología americana sobre un pueblo de los andes.

Entendemos que, al centrarse en el libro de Billie Jean Isbell, el autor busca golpear uno de los trabajos más influyentes del andinismo, corriente que es el objeto final de su crítica. Lamentablemente, al actuar así, opera una muy peligrosa reducción al endilgar a Isbell todos los defectos -reales o no- de la tendencia ideológica atacada. En lugar de convencer, esa amalgama nos hace más bien entrar en dudas sobre las verdaderas motivaciones de la crítica. No encontramos en todo caso una evaluación seria del trabajo mismo ni tampoco del paradigma dentro del cual se realizó de acuerdo a la propia autocritica de Isbell. La crítica se mueve más bien en el terreno ideológico y 
pierde entonces para nosotros gran parte de su interés. Me parece personalmente una lástima porque a los que trabajamos en el sur del continente, nos sería de mucha utilidad un balance serio de la historia teórica de los antropólogos del norte hecha por ellos mismos.

Al menos el autor del artículo reconoce que Billie Jean Isbell fue la primera en reconocer los limites de su trabajo al no haber advertido el futuro desarrollo de Sendero. Pese a ello, señala, "Isbell también conserva su misma visión de la continuidad y ensimismamiento andino". Y como prueba de ello, hace una cita deliberadamente trunca:

"Sendero ha declarado que está preparado para una lucha de cincuenta años para destruir el Estado existente $e$ instituir un nuevo orden. Los campesinos, por su lado, están concentrándose en preservar sus tierras y su forma de vida (Isbell 1985:xiii)".

La cita está recortada, pues el argumento continúa de la siguiente forma:

“... pero ellos están también transformando su estructura comunal al participar en una economía de mercado. Sendero ha atacado comunidades que han intentado librar productos a los mercados; han ejecutado también líderes comunales que no han apoyado la ideología de Sendero Luminoso." (la cursiva es mía)

Isbell, por lo demás es explícita en autocriticar su "perspectiva antropológica [que le] impidió ver los procesos históricos que estaban ocurriendo al mismo tiempo". Y, luego de reconocer el no haber ubicado adecuadamente Chuschi en el contexto de violencia creciente, ella continúa: 
"Los antropólogos debemos comenzar a aprender a compartir momentos de historia con aquellos a los que estudiamos. Esto nos apartará necesariamente del paradigma de las ciencias sociales que prevaleció en los años 1960 y 1970 y nos acercará al diálogo directo con nuestros antiguos sujetos de estudio. [...] Mi próximo paso personal será el de comprometerme en semejante diálogo con mis antiguos sujetos antropológicos de estudios, con miras a ubicar la violencia que está ocurriendo en la Zona Andina de Emergencia en una perspectiva histórica y política. Aun cuando haya tenido que cambiar mi visión un tanto romántica de la continuidad andina, yo quiero todavía creer que la cultura andina puede defenderse a sí misma de esa embestida actual." (Isbell 1985:xiv)

Personalmente, al igual que muchos antropólogos peruanos, no compartí el paradigma de las ciencias sociales al que se refiere Isbell y por ello resulta algo irónico que me coloque ahora a su lado frente a la crítica poco feliz de Starn. Es que, pese a sus limitaciones, siempre me ha parecido muy importante su trabajo (que lamentablemente -hasta donde tengo conocimiento- nunca ha sido traducido integramente al castellano). Superar un paradigma -como lo quería Kuhn, que introdujo el concepto- no significa echar por la borda todos los conocimientos acumulados, sino reubicarlos en otro contexto más amplio. Esto es precisamente lo que dice Isbell y por ello tiene toda la razón en seguir reivindicando una vigencia de la cultura andina. La crítica de Starn, a parte de ser muy sesgada como se ha visto, es meramente demoledora $y$ como tal no ayuda a avanzar.

Ahora bien, es desde luego completamente legitimo que los antropólogos "peruanistas" norteamericanos discutan entre ellos, desde sus propias categorias y a partir de sus propios fantasmas $y$ deseos. Pero si pretenden seguir 
trabajando sobre los Andes, a ellos mismos debería interesarles, aunque sea por mero interés profesional, saber algo de lo que aquí discutimos $e$ investigamos.

Es obvio en efecto que el artículo resulta un tanto extraño a nuestra problemática porque se ubica dentro de una nueva corriente de critica al llamado "orientalismo" que tiene gran auge en Estados Unidos. Pero el que se represente al Medio Oriente, según el autor, como "un lugar de romance, seres exóticos, recuerdos y paisajes fascinantes, y experiencias extraordinarias", tiene poco que ver, visto desde aquí, con los estudios serios sobre las sociedades orientales. Cuando un Arthur M. Hocart -por mencionar sólo uno de tantos- emprende desde El Cairo, en los años 30, un estudio comparado de rituales $y$ formas políticas, partiendo de un profundo conocimiento del mundo asiático, no se percibe en él ese tufillo "orientalista" criticado, que aparentemente tiene más bien que ver con la existencia en Estados Unidos de grupos religiosos orientados hacia el Oriente, cosa muy respetable por lo demás, aunque lo sean menos las múltiples derivaciones esotéricas de carácter más superficial inspiradas por el exotismo. Por otro lado, esa corriente de rechazo al "orientalismo" parece no ser tan casual en momentos en que Japón y otros países del Asia vienen apareciendo como posibles amenazas en Estados Unidos.

Que en ciertos círculos intelectuales norteamericanos se haya caído en visiones simplistas como las que se describe, no justifica una crítica tan ligera como la que se nos propone. Reconozco que ella debe de todos modos tener un aspecto sano si es leída desde el norte (para lo que fue escrita), pues alerta a ciertos círculos de antropologos norteamericanos contra las proyecciones de sus propios deseos y angustias que vienen haciendo sobre la sociedades "otras". Tomado de esa forma, el artículo cumple una función crítica que es propia de la tradición antropológica, aunque me cuesta creer -a pesar de que no lo pueda evaluar cabalmente por el poco acceso que se 
tiene en el Perú a la literatura producida allá- que los antropólogos norteamericanos en general sean tan ingenuos.

Todo ello nos muestra una discusión en la que allá y acá seguimos encerrados en contextos ideológicos bastante estrechos que son muy limitantes. Las ventajas de un diálogo norte-sur deberían sin embargo ser obvias para todos, siendo éstas mayores para los estudiosos del norte pues para ellos ese diálogo constituye casi una condición de su trabajo. Veamos este punto partiendo de dos aspectos centrales del artículo: la crítica del andinismo y el análisis de Sendero Luminoso.

1) El autor transpone al andinismo la crítica al orientalismo, arrastrando problemas similares. Asi por ejemplo, el texto asocia facilmente una visión de "la sierra como un lugar de culturas estáticas $e$ identidades rígidamente demarcadas" con "alegres afiches de emponchados campesinos andinos al lado de llamas en Macchu Picchu". Naturalmente coincido con la crítica a una visión estática de la cultura (¿quién no lo haría hoy?), pero el texto va más allá al dar a entender que la visión de la antropología sobre la cultura es la misma que la que aparece en los afiches de las agencias de viaje. ¿Tan pobre ha sido la antropología norteamericana? ¿Es esa la forma de discutir sobre el complejo problema de saber cómo estudiar procesos culturales de cambio, mezclas culturales, influencias de ámbitos culturales diversos? En su introducción de 1985, Isbell sugería preguntas más interesantes. $\mathrm{Y}$ en la antropología andina que conocemos en el Perú, aunque ciertamente no llegamos aún a comprender y calibrar cabalmente la relación entre continuidad y ruptura, este tema está a la orden del día y espero que lo podamos desarrollar sin necesidad de liquidarnos mutuamente. A quienes enfatizan la continuidad y dejan de lado el contexto histórico y social, es correcto llamarles la atención sobre la existencia de procesos de ruptura y la relación con un proceso social más amplio. Pero ello no significa que no hayan 
entendido nada $y$ menos aún que sus investigaciones no puedan ser recogidas en perspectivas más históricas.

El problema del cambio cultural en un país como el nuestro es demasiado serio y complicado como para que se lo resuelva con posturas apriorísticas como aquella que supone que, al no existir ninguna cultura andina vigente, entonces el que una señora hable de "nuestros antepasados incaicos" no significa otra cosa sino que "el andinismo ha completado el círculo", como lo dice el autor del artículo comentado. ¿Estamos volviendo a la idea de "alienación" del pueblo según la cual la gente del pueblo sólo repite ideas dominantes que no le convienen cuando nos dicen cosas que no corresponden a lo que esperaríamos? ¿Qué falta de seriedad en la argumentación!

A un trabajo que tiene límites autorreconocidos, pero que se ciñe al rigor científico (y cualquier trabajo científico es limitado por definición), no resulta un buen método descalificarlo contraponiéndole una crónica de viajes, pues el libro de Díaz Martínez no es otra cosa. Es cierto que como fuente este texto es interesante, pero lo sorprendente es que el autor no haya encontrado nada más entre los autores peruanos para discutir con Isbell. ¿Tan desconocidos son los antropólogos peruanos en los Estados Unidos?

La verdad es que la visión política sobre la sociedad andina no la inventó Díaz Martínez, es parte de la efervescencia en la Universidad de Huamanga de la época. El denunciar el sufrimiento y la explotación del campesino tiene por lo demás una ya larga tradición en el Perú. En Huamanga, José Carlos Mariátegui y José Maria Arguedas fueron dos puntos de partida importantes para los estudios de ciencias sociales. Es cierto que Sendero se fue olvidando del segundo y llegó a deformar completamente al primero con la idea del "pensamiento guía". Pero en Ayacucho, en los años 70, se generó un pensamiento crítico que, partiendo del marxismo, se fue entroncando con Arguedas en una búsqueda por trabajar 
los temas de la región y de la cultura. Sólo bastaría mencionar la revista Ideología en la que se debatieron importantes temas para la región, y nombres como los de Carlos Iván Degregori, Jaime Urrutia, Carlos Tapia, Modesto Gálvez, Lucía Cano y muchos otros que en esos años fuimos trabajando en torno a un análisis de tipo regional. A nivel nacional, no me atrevería a mencionar nombres, por el riesgo de olvidarme de muchos, pues se observó en el Perú una verdadera explosión de trabajos en ciencias sociales en los años 70, que nos ayudaron a formarnos una idea más cabal de lo que es nuestro Perú de hoy. Dentro de la limitaciones propias de un país como el nuestro, se ha ido prestando en los últimos años una atención renovada a los temas de cultura, reanudando más explícitamente con la tradición de Arguedas. Para quienes venimos trabajando en esa línea, el trabajo de Isbell, como muchos otros, siguen siendo de gran ayuda, aunque -como es lógico- nos reservamos el derecho de criticarlo en sus limitaciones. En ese sentido, la crítica demoledora de Stam no nos interesa porque nos pretende hacer creer que nada de ese trabajo sirve ya, que más acertado estuvo Díaz Martínez.

Me parece que, "andinistas" o no, los antropólogos norteamericanos metidos en la discusión sobre el "orientalismo" y que se interesan por el Perú tendrían mucho interés en conocer los debates que aquí se suscitaron desde los inicios del indigenismo. La perspectiva del complejo cultural vista por Arguedas representa en mi opinión un enorme avance que rompe con la dicotomía del indigenismo y critica así de antemano al "andinismo". Desde luego Arguedas ha sido objeto de polémicas en el Perú pero ha sido al mismo tiempo una muy importante referencia mucho más allá de la antropología, para todos quienes quieren entender el país. En la actualidad algunos consideran que es tiempo de abandonar el "paradigma de Arguedas", opinión que no comparto pero que, al plantearse de esa forma, muestra la importancia de Arguedas 
JuAN ANSION

en el desarrollo de nuestra manera de entender al país. Nadie que pretenda entender al país puede ignorar esto. 2) El segundo punto que merece observación es el análisis de Sendero. Tal vez lo que más irrita en el artículo, visto desde el Perú y más aún desde Ayacucho, sea que su crítica tan acerba termine por contraponer al estereotipo criticado otro estereotipo no menos equivocado: el de un país con guerrilla campesina, identificado con fosas comunes y soldados en pasamontañas. Muchos análisis torpes se han hecho sobre la violencia en el Perú. Uno de ellos es el de seguir viendo a Sendero como un producto campesino, que es la visión que asoma en el texto comentado. Lo curioso del caso es que Starn conoce y menciona a autores peruanos como Degregori y Manrique. Parece que la obsesión del autor por atacar a Isbell le hace perder la ponderación. Es cierto que Sendero tiene vínculos reales con el campo, pero si se lee a Degregori - a Gorriti, queda claro que no ha sido la expresión política de "un campo a punto de estallar en guerra" como lo sugiere el autor a partir de la lectura de Díaz Martínez (que no era, desde luego tan ingenuo como parece).

Es cierto que, al igual que las "docenas de etnógrafos [que] trabajaron en la sierra sur-andina durante los años 70", ninguno de nosotros creyó que un grupo tan dogmático como Sendero pudiera llegar a crecer en la forma como lo hizo. Nuestra ubicación en la universidad de Huamanga nos confrontó, sin embargo, con ellos de manera directa, dándonos elementos invalorables para entender su lógica. Desde ahí pudimos entender la frustración de jóvenes de origen rural y los vínculos que mantenian con sus lugares de origen, como elementos centrales del inicio de Sendero. $Y$ lo que percibimos, entonces, $y$ que la historia de la guerra ha venido confirmando, es que Sendero no nacía del movimiento campesino ni se originaba directamente en "el fuerte descontento de muchos campesinos contra el status quo". No es este el lugar 
para hacer un análisis desarrollado de Sendero, sólo basta recordar que ese grupo político, como lo señaló Degregori, inició su lucha armada después de haber sido derrotado en su intento por organizar una fuerza gremial campesina. Su apoyo inicial, como es notorio, estuvo en cambio en jóvenes estudiantes y en profesores rurales. Ese punto, que acabamos de confirmar en un estudio reciente, Isbell ya lo anticipaba de algún modo al referirse a la contraposición entre campesinos y profesores en su "Postdata - Cuatro años después" de 1975.

"Los campesinos de Chuschi han elegido una estrategia de protección de lo que tienen, mientras los profesores radicales de Chuschi han elegido estrategias para obtener lo que no tienen - mejores salarios, mayor movilidad social, y el poder para influenciar decisiones." (Isbell 1985:237)

Al tener que concluir este comentario que ya se extendió demasiado, siento que recién estoy llegando al momento de desarrollar en positivo los puntos que son verdaderamente de fondo: ¿cuál es la relación de Sendero con el campo? ¿cómo entender el cambio cultural? ¿sigue vigente la cuitura andina y qué significa? Estos son temas que siguen pendientes; se vienen trabajando y debatiendo en el Perú y sobre ellos existen muchos avances. Este comentario, sin embargo, se mantuvo en una cuestión previa: ¿cuánto se puede avanzar en la comprensión del Perú y de los andes prescindiendo de lo que pensamos y hacemos los peruanos?

Pese a mi acuerdo con muchas afirmaciones de Starn, discrepo con su manera de hacer la crítica porque no nos permite avanzar. Si queremos entender fenómenos como Sendero, las nuevas sectas religiosas, la lógica de los informales o la cultura política actual, tenemos que seguir estudiando los grandes temas de la antropología tales como las relaciones de parentesco, los rituales, las representacio- 
nes simbólicas. El libro de Isbell es ejemplar en ese sentido, aunque como bien lo reconoce la autora debe ser reubicado en su marco histórico y social. Esa confrontación -no vaga y general sino precisa y dentro del análisis mismo- permitirá un análisis certero que podrá ser de alguna utilidad. Por ello mi primera conclusión es el deseo de que el libro se pueda por fin editar en castellano para suscitar aquí el debate que se merece.

Mi segunda conclusión es una invocación a los colegas y amigos que investigan desde el exterior sobre los andes: no se encierren en sus propias discusiones, aprendan a dialogar con quienes conocemos bien el contexto histórico y social porque vivimos aquí. Ya verán que de ese modo se equivocarán menos...

Finalmente, mi última conclusión es para los antropólogos y científicos sociales peruanos: tenemos que seguir trabajando el tema de la transformación cultural rompiendo con esquemas ideológicos de toda índole y aprovechando todo lo avanzado. Con lo que sabemos en conjunto, una sintesis debe ser posible, pero ésta supone una capacidad de debate y de escucharnos mutuamente que sea mayor que la manifestada hasta ahora. 